\title{
INFLUENCE OF MOISTURE CONTENT AND LENGTH OF STORAGE ON FUNGAL INVASION OF PADDY RICE *)
}

\author{
DANILOE. PADERES \\ College of Agriculture, Department of Crop Protection \\ Central Luzon State University, Nueva Ecija, Philippines \\ T.W. MEW \\ Department of Plant Pathology, International Rice Research Institute \\ College, Laguna, Philippines \\ LINA L. ILAG \\ College of Agriculture, Department of Plant Pathology \\ University of the Philippines, College, Laguna, Philippines
}

\begin{abstract}
The relationship of moisture content and storage period to fungal population, seed germination, grain whiteness and translucency was determined.

Various fungal species predominated at different moisture conditions and storage periods. The fungi observed belong to the groups of Aspergillus flavus-oryzae, A. glaucus, A. mdulans. A. candidus, A. versicolor, A. terreus and A. niger and an unidentified species of Penicillium, Trichoconiella, Curvularia, Fusarium, Syncephalastrum and Verticillium. The predominant storage fungi were A. flavis-oryzae and A. candidus whereas, the predominant field fungi were Trichoconiella sp., Cun-ularia sp. and Syncepfialastrwn sp.

A decrease in the number of field fungi and an increase in the number of storage fungi with storage time were observed.

Storage fungi were noted as early as five weeks after storage at moisture contents from 9.3 to $18.33 \%$. The percentage germination of paddy remained high when stored at moisture contents of 9.3 to $14 \%$ but decreased with storage time at 14.5 to $18.33 \%$ moisture content. The percentage germination of paddy reached a peak at 10-15 weeks of storage. A significant negative correlation between percent germination and moisture content was observed. At 14.5-18.33\% moisture content, the germination of stored paddy decreased with a marked increase of storage molds.

Changes in grain whiteness was not affected by moisture content. However, a decrease in percent whiteness and translucency was noted after 25 weeks of storage.
\end{abstract}

Keywords: Stored products pests / Rice / Moisture content / Storage / Time / Fungi / Aspergillus sp. / Penicillium sp. / Trichoconiella sp. / Curvularia sp. / Fusarium sp./ Syncephalastrum sp. / Verticillium sp.

*) Paper presented at the Symposium on Pest Management for Stored Food and Feed, 5-7 September 1995, Bogor, Indonesia 


\section{Morphological and Cultural Characteristics of the Different Groups of Aspergillus}

A. flavus-oryzae. Colonies on Czapek's solution agar grew rapidly, reaching a diameter of 5.5-6.0 $\mathrm{cm}$ after 10 days incubation at room temperature. Vegetative mycelium was largely submerged with loose texture, surface growth of long-stalked conidial structures and intermixed aerial mycelium. At first, conidial heads appeared white and later developed to a pale greenish yellow to deep yellow-green or olive-brown when mature. Globose black sclerotia were produced with" age. Conidial heads were predominantly large arising from a long colorless conidiophore. Vesicles are typically subglobose bearing either uniseriate or biseriate sterigmata consisting of subglobose conidia.

A. glaucus. Colonies on Czapek's solution agar reached a diameter of 1-1.5 cm after 10 days of incubation at room temperature. Conidial heads were typically bluish-green. Smooth-walled and brown colored conidiophore terminated to a domelike vesicle. Conidia arising from a uniseriate sterigmata were typically globose to subglobose in chains. Cleistothecia, yellow and subglobose were present.

A, nidulans. Growth in Czapek's solution agar reached a diameter of 5-6 cm in 10 days at room temperature. Conidial heads were usually dark green, short columnar. Conidiophores were smooth and light brown in color which terminated to hemispherical vesicle bearing a biseriate sterigmata. The primary and secondary sterigmata were about equal in length. Conidia were globose and echinulate.

A. candidus. This organism was easily detected by having white condial heads when young and becoming yellowish cream in age. Colonies in Czapek's solution agar had a diameter of 2.5-3.0 cm after 10 days incubation at room temperature. Conidiophores were smooth colorless bearing globose to subglobose vesicle with biseriate sterigmata.

A. versicolor. The size of the colonies on Czapek's solution agar reached a diameter of $1.5 \mathrm{~cm}$ in 10 days at room temperature. This organism has radiate to loosely columnar conidial heads. The brown conidiophore terminated to an ovate or elliptical vesicle. The echinulate conidia are attached to a strictly biseriate sterigmata.

A. terreus. Colonies on Czapek's solution agar obtained a diameter of $4-5 \mathrm{~cm}$. It can easily be identified because of its brighter color in buff, cinnamon, to orange brown compactly columnar conidial heads. The vesicles were hemispherical attached to biseriate sterigmata where globose, smooth conidia were borne.

A. niger. This fungus is similar to A. flavus-oryzae by its rapid and vigorous growth on Czapek's solution agar which reached a diameter of $2.5-4.0 \mathrm{~cm}$ after 10 days at room temperature. Conidial heads were in black dark brown shades. Conidiophores coming from submerged mycelia terminated to a globose vesicle. The vesicles consisted of biseriate sterigmata where subglobose, elliptical conidia were borne. 


\section{DISCUSSION}

Moisture content is known to be the primary contributing factor in determining the kinds of fungi that invade stored seed and the degree to which they invade it (Coleman and Fellow 1925; and Koehler 1938). In the present study, the predominant fungal species tended to vary at different moisture levels. The variation in the percent fungal incidence found either on or in the seed may probably be due to the competition among organisms. There are fast and slow invading molds (Neegaard and Adib Saad 1962). Some fungi may overgrow and obscure other species, thus preventing their identification. Overgrowth of one species by another may result from an inherent growth rate difference between species (Schroeder and Sorenson 1961).

Expectedly, high percentages mold infection were observed in paddy stored at high moisture content levels. The predominant fungi found in grains with high moisture content were $A$. flavus- oryzae, A. glaucus and A. candidus. These findings agree with those of Tuite and Christensen (1957), Bottomley et al. (1952) and Del Prado and Christensen (1952) on stored cereal seeds, corn and rice, respectively.

The decrease in the germination of rice may be attributed to the ability of the fungi to grow on rice grains. At 14.5-18.33\% moisture content, the rice grains showed a marked increase in mold infection. Similar findings were reported by Del Prado and Christensen (1952), Tuite and Christensen (1957) and Christensen and Lopez (1965) in stored rice seeds.

Christensen and Kaufmann (1965) stated that different species of storage fungi require certain limit of moisture content for growth which determines the range over which they will predominate. They further claimed that in the starchy cereal seeds, the lower limits of moisture content that permit invasion by the common storage fungi were: Aspergillus halophilicus, 13.0 to $13.2 \%$; A. restrictus, 13.2 to $13.5 \%$; A. amstelodami, A. chevalleri, A. repens and A. ruber, 14.0 to $14.2 \%$; A. candidus and A. ochraceus, 15.0 to $15.2 \%$; A. flavus, 17.5 to $18.0 \%$. Christensen and Sauer (1982) also reported the different lower limits of fungi for growth in starchy cereal seeds as follows: A. halophilicus 13.0 to $14.0 \%$; A. restrictus, A. glaucus, A. candidus and A. ochraceus, 14.5 to $16.0 \%$; A. flavus and Penicillium spp., 16.0 to 20.0\%. Likewise, Christensen and Lopez (1965) reported the invasion of storage fungi on rough rice took over at grain moisture contents of $13.4-13.8 \%$.

In the present study, storage fungi such as A. flavus-oryzae, A. candidus and A. glaucus were detected in rice grains stored at very low moisture contents (9.3-11.3\%). These moisture levels are much lower than the lower limits for growth reported by other workers specially for $A$. candidus (Christensen and Kaufmann 1965; and Christensen and Sauer 1982). 
The succession of field fungi by storage fungi during storage observed in the present study agrees with the results of Quitco (1982) and those at IRRI (1977).

The percent whiteness and translucency of milled rice showed varying results. Thus, the relationship of moisture content and mold count on grain whiteness and translucency needs further studies.

\section{CONCLUSION}

Fungi associated with stored rice were A. flavus-orywe, A. glaucus, A. nidulans, A. candidus, A. versicolor, A. terreus, A. niger, and species of Penicillium, Trichoconiella, Curvularia, Fusarium, Syncephalastrum and Verticillium. A high fungal population of the species of Aspergillus were noted in rice paddy stored at high moisture content level.

Seed germination of rice remained high in rice stored at moisture contents from 9.3 to $14.0 \%$ and markedly decreased from 14.5 to $18.33 \%$ moisture content. Likewise, an increase of storage fungi and decrease of field fungi was observed with increased storage period. The high mold count obtained from grain with high moisture levels favorable for growth of various species of Aspergillus has contributed to decrease in seed germination.

\section{REFERENCES}

BEUCHAT, L.R. 1984. Survival of Aspergillus flavs conidiospores and other fungi on cowpeas during long term storage under various environmental conditions. J. Stored Prod. Res. 21:47-52.

BOTTOMLEY.R.A. C.M. CHRISTENSEN, and W.F. GEDDES. 1952. Grain storage studies. X. The influence of aeration, time and moisture content on fat acidity, non-reducing sugars, and mold flora on stored yellow gram. Cereal Chem. 29: $53-64$.

CHRISTENSEN. C.M. 1967. Germinability of seeds free of and invaded by storage fungi. Proc. Assoc. Seed Analysts?: 141-143.

CHRISTENSEN. C.M. and H.H. KAUFMANN. 1965. Deterioration of stored grains by fungi. Ann. Rev. Phytopathol. 3: 69-84.

CHRISTENSEN. C.M. and L.C. LOPEZ. 1965. Relation of moisture content and length of storage to changes in the microflora and germination percentage of rough rice. Phytopathology 55: 953-956.

CHRISTENSEN, C.M. and D.B. SAUER. 1982. Microflora. In Storage of Cereal Grains and Their Products. C.M. Christensen (ed). American Association of Cereal Chemist Inc. St. Paul Minnesota, p. 219- 240.

COLEMAN. D.A. and H.C. FELLOWS. 1925. Hygroscopic moisture of cereal grains and flaxseed exposed to atmospheres of different relative humidity. Cereal Chem. 2: 275-287.

DAVID. M.W., E. JAY, and R.A. HILL. 1985. Microflora changes in peanuts (groundnuts) stored under modified atmospheres. J. Stored Prod. Res. 21: 47-52. 


\section{Influence of moisture content - Danilo E. Paderes et. al}

DEL PRADO, F.A. and C.M. CHRISTENSEN. 1952. Grain storage studies. XII. The fungus flora of stored rice seeds. Cereal Chem. 29: 456- 462.

FANDIALAN, I.M. and L.L. ILAG. 1973. Aflatoxin production ofAspergillusflavus Link, isolates from rough rice, corn, sorghum, peanut and copra. Phill. Agric. 57: 254-263.

INTERNATIONAL RICERESEARCH INSTITUTE. 1977. Annual report. College, Laguna, Philippines, p. 177-178.

INTERNATIONAL SEED TESTING ASSOCIATIONS. 1976. International seed testing association rules. Seed Sci. and Technol. 4:51-177.

KOEHLER, B. 1938. Fungus growth in shelled corn as affected by moisture. J. Agr. Res. 56: 291-307.

MALLICK, A.K. and B. NANDL 1982. Deterioration of rough rice 3. Volatile compounds in short term preservation of grains. Seed Sci. and Technol. 10: 315-320.

NEERGAARD, P. and ADIB-SAAD. 1962. Some seedborne diseases and their control. Indian Council Agr. Res. 44 p.

QUASEM. S.A. and C.M. CHRISTENSEN. 1958. Influence of moisture content, temperature and time on the deterioration of stored corn by fungi. Phytopathology 48: 544-549.

Qurrco, R.T. 1982. Paddy deterioration from procurement to storage. NAPHIRE Tech. Bul. No. 2, FTT Complex, MM, Philippines.

Qurrco. R.T. and L.L. ILAG. 1982. Fungi as a cause of yellowing and other discolorations of rice. Proc. 5th Workshop Grains Postharvest Technology, p. 118-123.

RAPER, K.B. and D.I. FENNEL. 1977. The genus Aspergillus. Robert E. Krieger Pub. Co., Huntington, New York. 686 p.

SCHROEDER, H.W. and J.W. SORENSON JR. 1961. Mold development in rough rice as affected by aeration during storage. Rice Journal 64: 21-23.

TUITE. J.F. and C.M. CHRISTENSEN. 1957. Moisture content of wheat seed in reladon to invasion of the seed by species of the Aspergillus glaucus group and effect of invasion upon germination of the seed. Phytopathology 47: 323-327.

VAIDEHI, B.K. and S. WAGHRAY. 1982. Storage fungi of paddy and their role in seed deterioration. National Seminar on Seed Pathology. Dept. of Plant Pathology. Tamil Nadu Agricultural University. India, p. 17-19. 


\section{INTRODUCTION}

Rice (Oryza sativa Linn.) is one of the worlds major food crops. In rice producing regions where the relative humidity often ranges from 60 to $90 \%$ and the prevailing temperature is high, it has been found that these conditions are conducive for microbial growth. Field and storage fungi rapidly multiply, thus affecting the quality of stored rice seeds.

The dominant and often the only fungi present on stored rice paddy are species of the genus Aspergillus (Mallick and Nandi 1982; and Vaidehi and Waghray 1982). Like seedborne pathogens, Aspergillus spp. are also responsible for the decrease in percentage of seed germination (Christensen 1967) and enhance damage or discoloration of glumes (Quitco and Hag 1982) and aflatoxin formation (Fandialan and Hag 1973).

Studies have been conducted on the effect of physical factors on stored corn (Quasem and Christensen 1958X wheat (Tuite and Christensen 1957), peanuts (David et al. 1985) and cowpeas (Beuchat 1984) but there are few studies focusing on stored rice.

Since most of the researches on storage fungi have been conducted under temperate and arid tropical conditions, this study identified the storage fungi affecting rice grains and determined the relation of moisture content and length of storage to the predominant mycoflora and on grain deterioration.

\section{MATERIALS AND METHODS}

IR60 paddy rice seeds were used in the study. The paddy were sundried to moisture contents ranging to $9.33 \%$ and $10.56 \%$. Five $150 \mathrm{~g}$ paddy rice samples inside small sacks were placed in each desiccator containing super saturated solution of reagent salts, namely: potassium nitrate, potassium chloride and sodium chloride. Constant temperature of $22^{\circ} \mathrm{C}$ was maintained by an incubator which can accommodate 12 desiccators. At every five weeks interval, the desiccators were opened and one sack in each treatment replicated three times including the control was taken and the moisture content, percent seed germination, percent whiteness, translucency and presence of fungi were determined.

\section{Moisture Content}

The high constant temperature oven method of determining seed moisture content based on the International Seed Testing Association rules (1976) was used. Twenty grams of seeds were taken in each treatment including the control and placed inside a brown paper envelope. The envelopes containing the seeds were dried inside the circulating air oven for three hours maintained at $13^{\circ} \mathrm{C}$. The envelopes were cooled in a 
desiccator above silica gel for 30 minutes and weighed. The seed moisture content was calculated on the wet weight basis.

The experimental layout consisted of a split plot design with three replications. The different salts and the control were assigned to the main plot and storage period to the subplots.

\section{Percentage germination}

The percentage germination test was adapted from Christensen and Lopez (1965) with some modifications. That is, 400 instead of 100 seeds taken from each treatment including the control were used. The seeds were surface sterilized with $20 \%$ of $5.25 \%$ sodium hypochlorite for $10 \mathrm{~min}$. and spaced on blotter moistened in sterile water with 100 seeds in each petri dish. The seeds were incubated at room temperature for 7 days. A seed which produced a root or coleoptile was considered to have germinated. The relationship of moisture content and percentage germination was determined.

\section{Percent Whiteness}

A Kelt Whiteness Meter was used to determine the percent whiteness of milled rice. The whiteness meter was conditioned for $30 \mathrm{~min}$. before a sample was placed inside the apparatus. Approximately $35 \mathrm{~g}$ of milled rice from each treatment and the control were placed inside the whiteness meter. Each sample was read three times in all the treatments and the control.

\section{Translucency}

A rice meter was used to calibrate the translucency of rice grain. The rice meter was conditioned for $30 \mathrm{~min}$. before a sample was placed inside the loading disk. A standard value of $83.0 \%$ was used to calibrate the sample. Twenty five grams of milled rice from each treatment and the control were placed inside the loading disk. A corresponding value of the translucency of the samples was registered and recorded. Each sample was read three time.

A split plot design with moisture contents assigned to the main plot and storage period to the subplot was followed.

\section{Storage fungi}

Four hundred seeds from each of the treatments and the control were disinfected with $5.25 \%$ sodium hypochlorite for $1 \mathrm{~min}$. and spaced in malt salt agar, usually 25 seeds in each petri dish and incubated at $25^{\circ} \mathrm{C}$ for 7 days. The kinds and numbers of storage 
fungi were observed using a stereobinocular microscope. Fungi showing identical cultural characteristics were grouped together to determine the number of fungi associated on the seeds. A series of transfers were made to obtain a pure culture of the fungus.

Czapek's solution agar was used as the medium for identifying the isolates belonging to the genus Aspergillus. Three point inoculation was used as one of the basis of identification of the genus Aspergillus (Raper and Fennel 1977). Spores from the purified slants were suspended in melted agar at approximately $45^{\circ} \mathrm{C}$. Using a cork borer small amounts of the inoculated gelled medium were planted on desired spots on the previously plated Czapek's solution agar. The plates were incubated for 10 days at $25^{\circ} \mathrm{C}$.

The numbers of storage molds, as affected by levels of moisture content and storage period, were analyzed using split split plot design. The levels of moisture content were assigned to the main plot, storage period to the subplot and the fungal genera to the subsubplot.

\section{RESULTS}

Rice paddy stored in different salt solutions as well as storage period had different moisture contents (Fig. 1). The equilibrium moisture content provided by the different

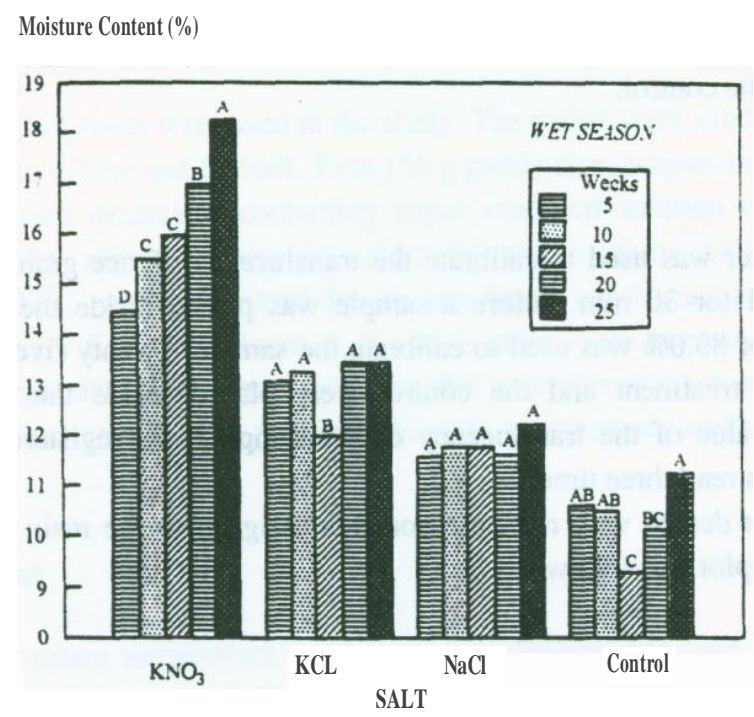

Figure 1. Mean moisture contents of paddy stored in different salt solution and storage periods. Bars having the same letter in each salt solution are not significantly different at $5 \%$ by DMRT. 
salt treatments was highest in potassium nitrate, followed by potassium chloride, then with sodium chloride and the control after 25 weeks storage. The moisture content of the paddy stored in potassium chloride and the control varied with sampling time. However, an increasing trend of moisture content with storage period was noted in grains stored in potassium nitrate. There was no significant differences in moisture content of paddy stored in sodium chloride.

\section{Effect of Moisture Contents and Length of Storage on Seed Germination}

The germination of stored paddy was affected by moisture content. At $14.5-18.3 \%$ moisture content, the percentage germination increased at 10 and 15 weeks of storage but decreased with further storage (Fig. 2). Rice seeds stored after 5 weeks still remained

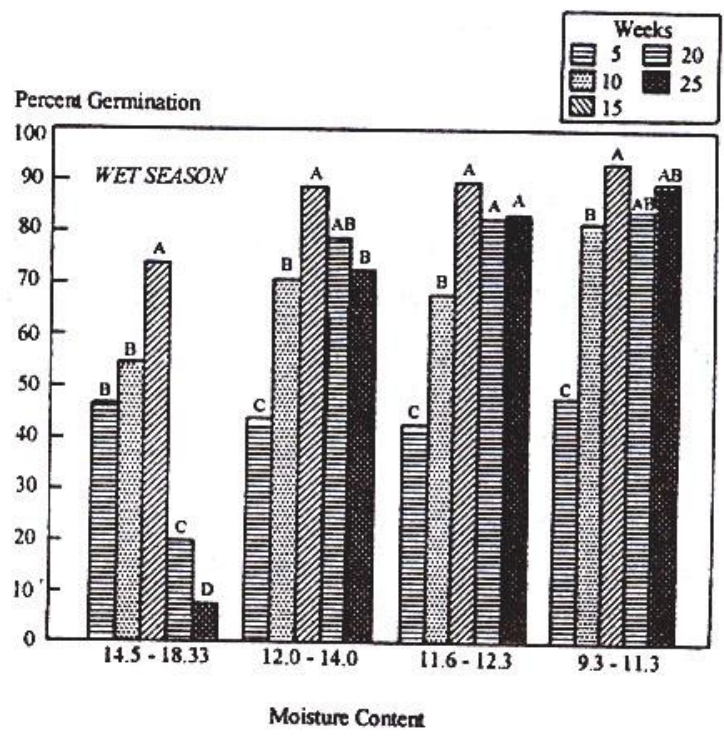

Figure 2. Mean percent germination of paddy stored at different time intervals. Bars having the same letter at each moisture content level are not significantly different at $5 \%$ by DMRT.

dormant, hence, no significant differences were observed in the percentage germination of rice seeds at all levels of moisture content. The percentage germination did not vary significantly at 15,20 and 25 weeks of storage at moisture content level from 9.3 to $14 \%$. However, at higher moisture levels (14.5-18.33\%), the percentage germination significantly decreased at 20 and 25 weeks of storage (Fig. 3). 


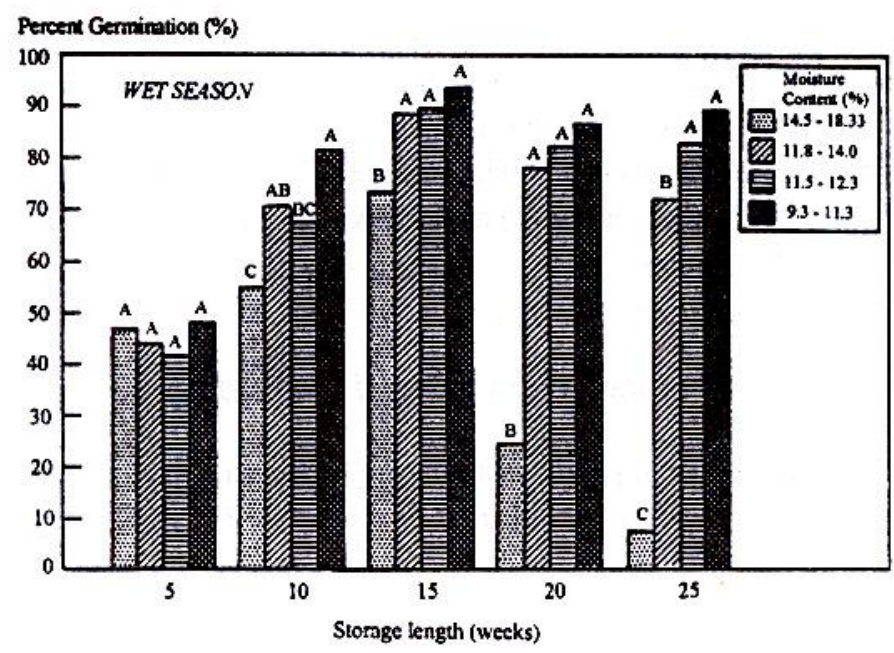

Figure 3. Mean percent germination of paddy stored at different moisture conditions. Bars having the same letter in each storage period are not significantly different at $5 \%$ by DMRT.

There was a negative correlation between moisture content and percentage germination with a correlation coefficient (r), of - 0.61 (Fig. 4).

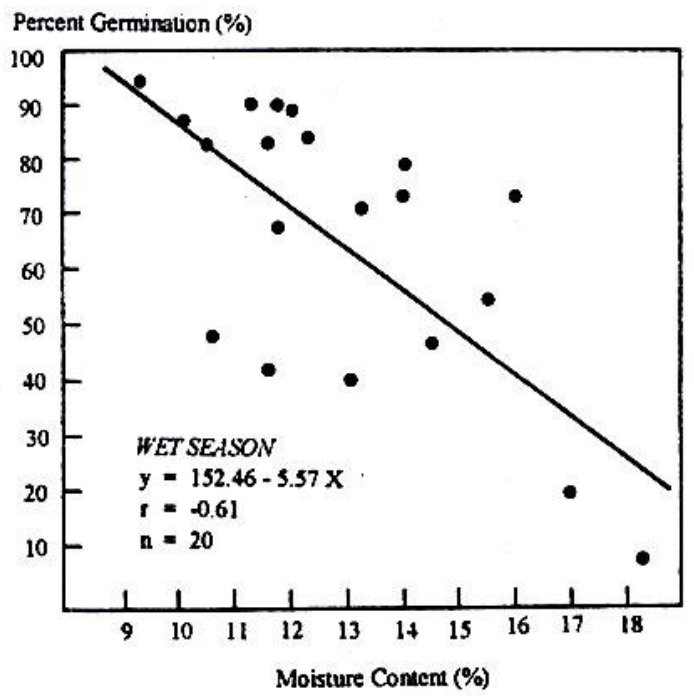

Figure 4. Relationship between percent germination and moisture contents of stored rice 


\section{Effect of Moisture Content and Length of Storage on Grain Whiteness and Translucency}

Figure 5 illustrates the effect of moisture content and length of storage on the percent whiteness of milled rice. The percent whiteness did not vary significantly at the different moisture content levels. However, there was a decrease in percent whiteness of milled rice at 25 weeks of storage.

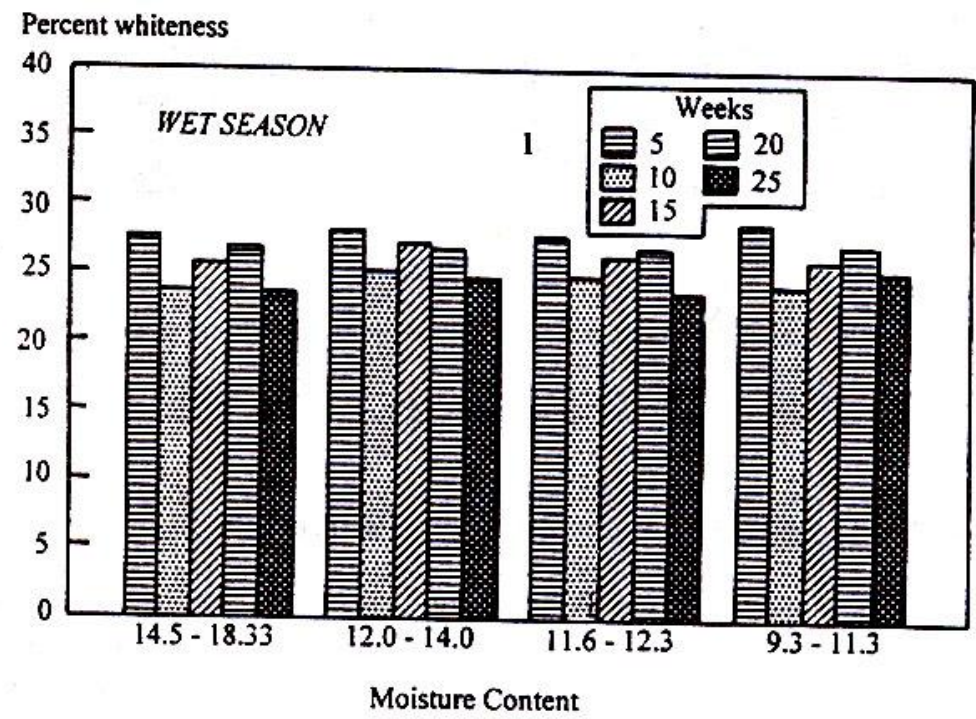

Figure 5. Mean percent whiteness of milled rice stored in different moisture conditions and storage period. Vertical bar (1) indicates $1 \mathrm{SD}(0.05)$.

The effect of moisture contents and length of storage on the translucency of grains is presented in Fig. 6. There were fluctuations in the translucency of the paddy stored at moisture contents $9.3-11.3 \%$ and $12.0-14.0 \%$ with time. No significant differences were noted on the translucency of paddy at $14.5-18.33 \%$ moisture content. From 11.6 to $12.3 \%$ moisture content, the translucency of paddy taken after 5 weeks was significantly higher than the succeeding sampling periods 


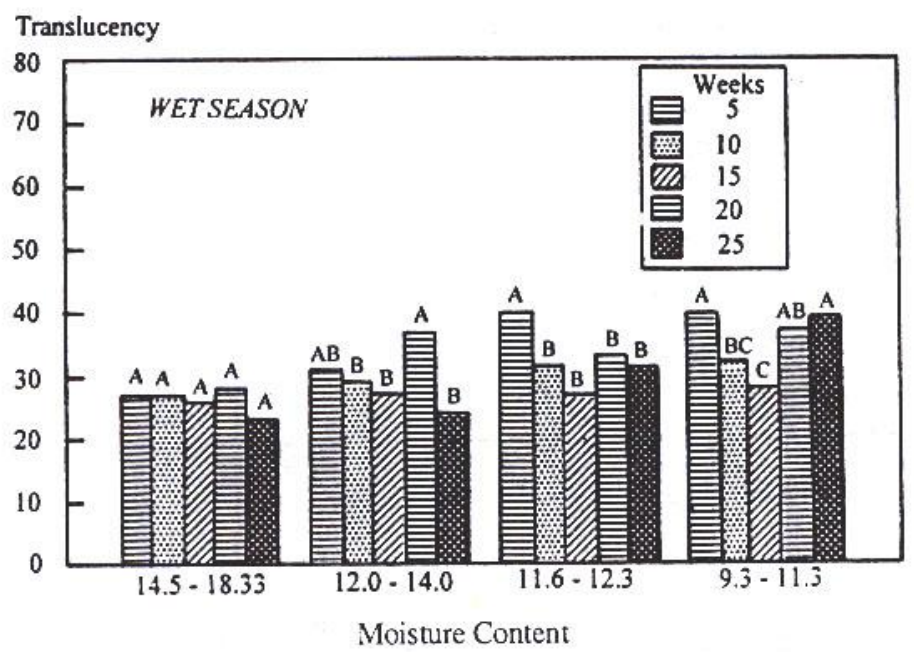

Figure 6. Mean translucency of milled rice stored in different moisture conditions and storage period. Bars having the same letter at each moisture content level are not significantly different at $5 \%$ by DMRT.

\section{Fungi Associated with Rice Stored in Different Moisture Contents}

The majority of the fungal genera that were consistently associated with stored rice belong to the genus Aspergillus. The vegetative mycelium consisted of septate branching hyphae. Conidial apparatus developed as conidiophore and head from specialized, enlarged, thick walled hyphal cells. Conidiophore originated from a foot cell and enlarging upward and broadening into fertile vesicles. The vesicles bore fertile cells or sterigmata producing spores or conidia borne successively from the tips of the sterigmata. Further characterization of the Aspergillus into group level was revealed by the different reactions of 3 point inoculation on Czapek's solution agar. The cultural and morphological characteristics of the different genera were revealed by agar block technique.

The isolated fungal genera were Aspergillus flavus-oryzae, $A$. glaucus, $A$. nidulans, $A$. candidus, A. versicolor, A. terreus, A. niger, Penicillium, Trichoconiella, Curvularia, Fusarium, Syncephalastrwn and Verticillium. The percentage fungal incidence varied with moisture levels. There was a shift in the number of different fungal species with storage period at different moisture levels. At 5 weeks of storage, field fungi (Curvularia, Trichoconiella and Fusarium) had higher fungal incidence and these markedly decreased with prolonged storage at all moisture levels (Figs. 7 and 8). The storage fungi (A. flavus-oryzae, A. glaucus and $A$. candidus) slowly increased with storage period until they became the predominant fungi after 25 weeks of storage. 


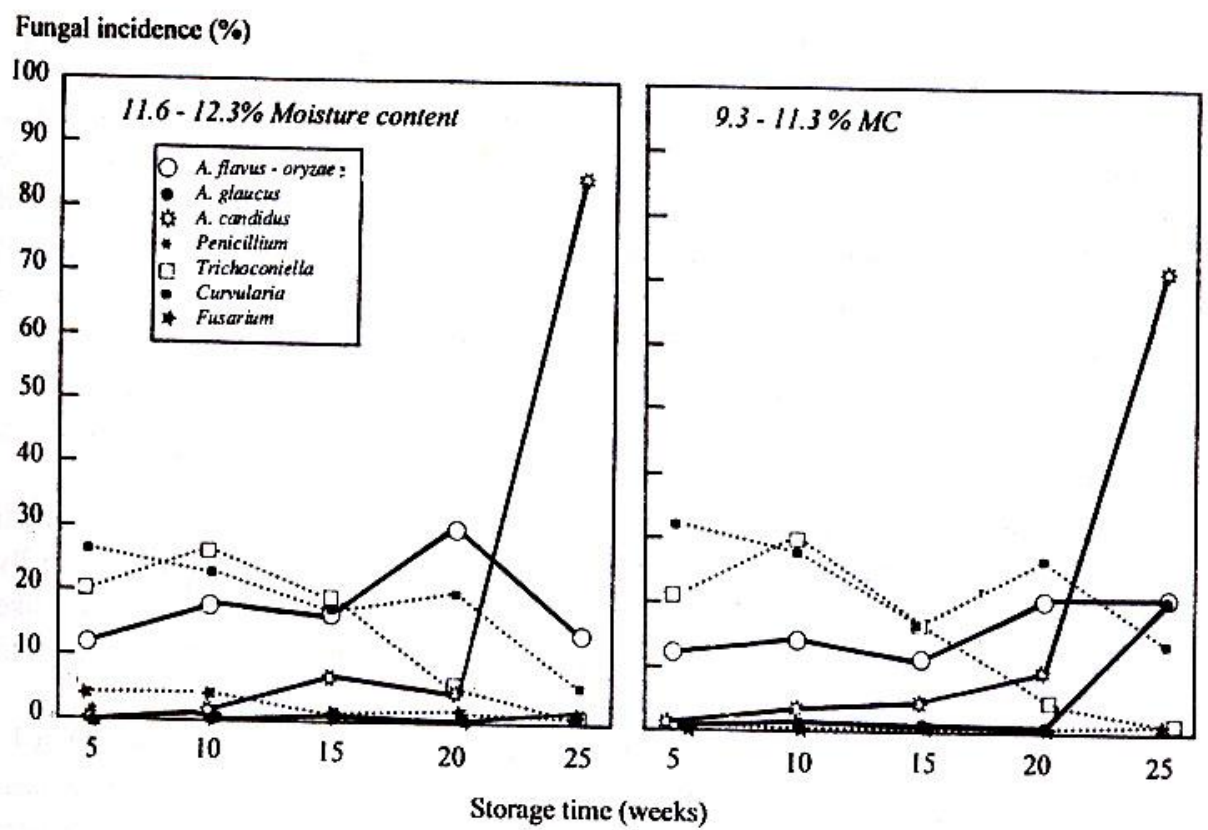

Figure 7. Fungal incidence in rice paddy stored for 25 weeks at $9.3-11.3 \%$ and $11.6-12.35 \%$ moisture contents

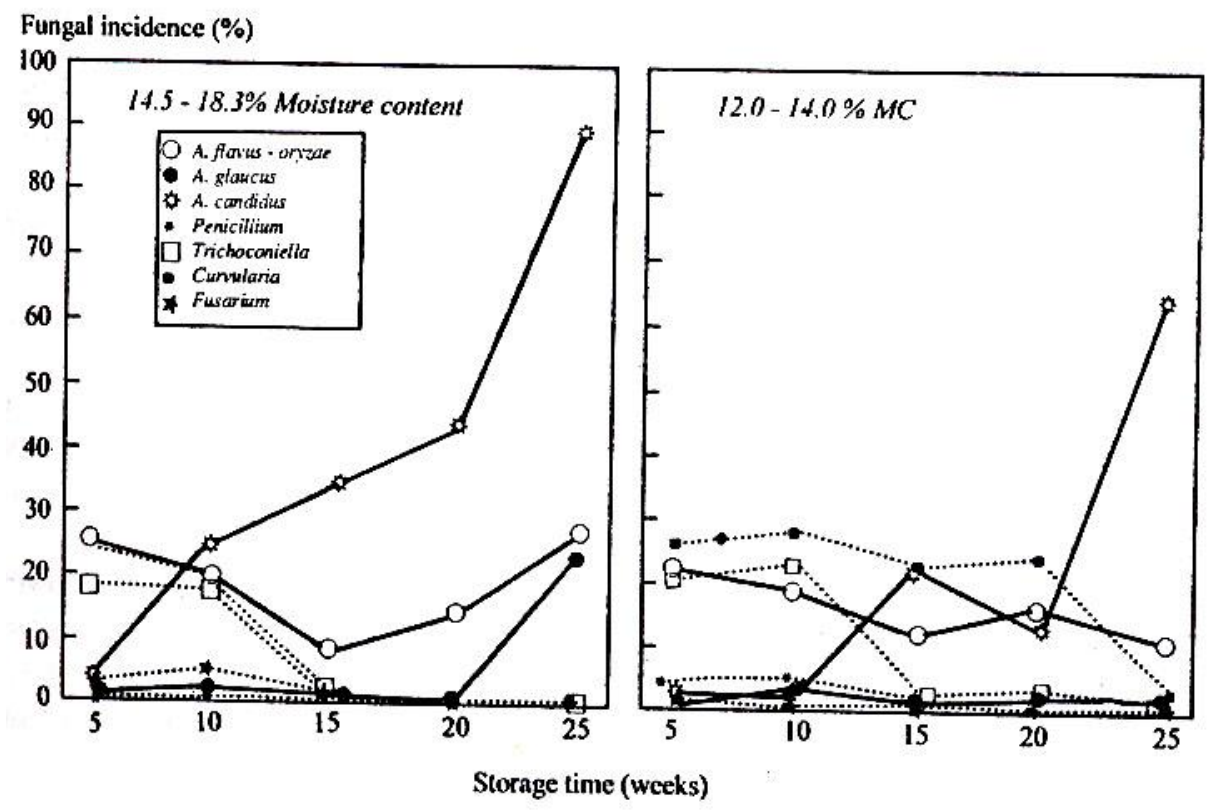

Figure 8. Fungal incidence in rice paddy stored for 25 weeks at $12.014 .0 \%$ and $14.4-18.3 \%$ moisture contents 